\title{
Introducción de la dimensión ambiental en el proceso de Universalización de la Enseñanza Superior Cubana
}

\author{
Célida Valdés Menocal \\ (Universidad de La Habana. Cuba)
}

\section{Resumen}

En la actualidad la temática ambiental juega un papel esencial, dadas las sucesivas catástrofes ecológicas mundiales que han conllevado a una toma de conciencia general de los daños que ha sufrido y sufre la naturaleza y un amplio consenso de la urgencia de conservar y proteger a la Tierra.

Estos acontecimientos han conllevado a que se realicen cambios en la Educación Cubana lo que se manifiesta en la introducción de la dimensión ambiental en los planes de estudios de las carreras universitarias y en particular en la carrera de Estudios Socio-Culturales, en la cual se persigue un profesional con la Cultura General Integral que pueda enfrentar los retos del siglo XXI.

Nuestro país se ha enfrascado en el desarrollo lo que denominamos "la municipalización de la enseñanza superior": una modalidad de educación válida para los jóvenes egresados de los cursos de maestros y otros programas, constituye una vía para la promoción popular de conocimientos, aproxima la universidad al municipio, a la comunidad y a la persona. Sus claustros están conformados por profesionales de la comunidad que en horario nocturno, se desempeñan como profesores bajo la asesoría docente-metodológica de profesores universitarios, de reconocido prestigio y excelencia académica.

\section{Palabras clave}

Universalización - Responsabilidad - Educación - Dimensión Ambiental - Conciencia Ambiental.

\section{Summary}

Today environmental issues play a crucial role given the successive global ecological disasters have led to a general awareness of the damage it has suffered and is suffering nature and a broad consensus on the urgency to conserve and protect the Earth.

These developments have led to changes being made in Cuban education as manifested in the introduction of the environmental dimension in the curricula of 
university courses and particularly in the career of Socio-Cultural Studies, which is pursued a professional with the general culture that can meet the challenges of the $\mathrm{XXI}$ century.

Our country has been engaged in developing what we call "the municipalization of higher education", which means a valid form of education for young graduates of teacher training and other programs, is a popular way of promoting knowledge, approaches university to the municipality, the community and the person. Its cloisters are made by professional community at night, act as teachers under the guidance of teachers teaching methodological university of recognized standing and academic excellence.

\section{Key words}

Universalization - Responsibility - Education - Environmental Dimension - Environmental Consciousness - Awareness - Municipalization.

\section{Introducción}

Cultura es lo que salva del naufragio vital, lo que permite al hombre vivir sin que su vida sea tragedia sin sentido o radical envilecimiento... -Ortega y Gasset-

Los cambios en la Educación Cubana han conducido a la introducción de la dimensión ambiental en los planes de estudios de las carreras universitarias y, en particular, en la de Estudios Socio-Culturales, en la cual se persigue un profesional con una Cultura General Integral que pueda enfrentar los retos del siglo XXI.

¿Qué podemos hacer los educadores cubanos para profundizar en la enseñanza de lo ambiental?

Siguiendo la línea de nuestro Héroe Nacional José Martí (1853-1895): "Educar es depositar en cada hombre toda la obra humana que le ha antecedido: es hacer a cada hombre resumen del mundo viviente". "Un pueblo de hombres educados será siempre un pueblo de hombres libres" (1).

Sin dudas, los elementos de la educación y en especial de la ambiental deben estar presentes desde las edades tempranas, donde vamos a conformar convicciones, comportamientos, conductas y actitudes. Pero al mismo tiempo, se debe trabajar en aquellos jóvenes adolescentes que no han recibido la educación ni la instrucción suficiente sobre lo que significa lo ambiental y debe brindárseles esos instrumentos en el nivel medio y superior.

Afirmamos que la educación ha de tener como objetivo el perfeccionamiento de las virtudes del hombre, la maduración del ser humano, el despliegue de sus potencialidades como sujeto en la historia. 
En la historia del pensamiento cubano, las referencias a lo educativo son cardinales en figuras de la relevancia del presbítero Félix Varela (1787-1853), quien siempre estuvo enfrascado en el mejoramiento humano, y se apoyó en lo imperioso de contar con un sistema de educación que condicionara la formación de una conciencia con ciencia. Asimismo, el maestro José de La Luz y Caballero (1800-1862), cuya vida y obra estuvieron enfocadas a la formación de hombres con una moralidad que respondiese al momento histórico, vinculó los problemas y las necesidades de su tiempo con el conocimiento de la realidad social. La educación para él era un medio que permitía "templar el alma para la vida".

El Apóstol José Martí en su ensayo "Nuestra América" defiende la unidad entre educación y práctica revolucionaria, en el sentido de renovar lo existente para lograr no sólo instrucción sino educación como único modo de ser libre. Además, le ofrece un papel muy destacado a la escuela, su vínculo con la familia y con las diversas organizaciones que conforman la vida social y el contexto de ese momento.

El pensador y pedagogo Enrique José Varona (1849-1933) es uno de los primeros en Cuba en realizar una reforma en el sistema de instrucción, al plantear que está incluida como un elemento más dentro del proceso educativo. Desde esta visión, ayuda a elevar a planos superiores la moral del individuo, y encaminarlo al mejoramiento humano con un sentido liberal y democrático.

Con el triunfo de la Revolución en 1959, se concibió lo educativo como condición esencial de la emancipación del individuo, valorando lo significativo del proceso de perfectibilidad en el comportamiento humano: el eje ha sido el desarrollo integral del hombre y la sociedad, con vistas a la responsabilidad social para el logro de una serie de metas que conlleven a la justicia, igualdad, equidad y sostenibilidad.

En los años 60 del siglo XX, se lleva a cabo el proceso de Alfabetización, como primer paso de una profunda Revolución Educacional que había tratado de desarrollar en la década del 20 el joven revolucionario Julio Antonio Mella con la Educación Popular.

Los cambios sociales en 1970 y 1980 posibilitaron el acceso gratuito y masivo de amplios sectores sociales a la educación y a la cultura. Los esfuerzos se encaminaron al perfeccionamiento del Sistema Educacional Nacional, buscando la superación de los profesores y maestros con el fin de cumplir con los requerimientos que demanda la formación de nuevas generaciones.

Ahora bien, la década de los 90 marcan un período trascendental en nuestra historia, con el derrumbe del campo socialista, el Muro de Berlín, la desintegración de la Unión Soviética (URSS), el recrudecimiento del Bloqueo Económico, Político y Cultural de Estados Unidos de Norteamérica, lo que condujo a una afectación en los niveles de vida del cubano. La vida material y espiritual del ciudadano se complejizó hasta llegar a niveles de pobreza que 
con la Revolución de 1959 se habían superado. Como resultado, comienzan a surgir actitudes poco solidarias y altruistas y que reforzaron los valores negativos, sobre todo en un sector muy sensible: los jóvenes.

En 1999 sucedió un hecho que marcó el decursar sociopolítico y cultural de la Revolución Cubana: el secuestro del niño Elián González por sus familiares en Miami y la lucha que junto a su padre llevó el pueblo cubano por su devolución a la Isla.

Los sucesos condujeron a que las máximas autoridades del país realizaran un análisis profundo sobre los comportamientos, actitudes y estilos de vida del sector joven de la población y se llegara a la conclusión de que había que reforzar las esferas educativas y culturales. Ante el llamado del Comandante en Jefe Fidel Castro en el año 2000 se inicia una profunda transformación del Sistema Nacional de Educación, donde se instrumentan planes y programas nacionales como la Batalla de Ideas, la Cultura General Integral, y la Universalización de la Enseñanza dirigidos a toda la población para complementar y profundizar la educación recibida por las vías tradicionales.

\section{El modelo pedagógico cubano}

El aumento significativo del número de jóvenes desvinculados del trabajo y el estudio dio inicio, según las profesoras de La Universidad de La Habana, Mercedes Valdés y Nancy López, a un programa esencial: la formación emergente de trabajadores sociales para satisfacer las necesidades del país en las nuevas circunstancias de crisis económica y la implementación de medidas por el Gobierno Revolucionario para contrarrestarla (2).

En el año 2000 se inaugura la primera escuela de Trabajadores Sociales en La Ciudad de La Habana, posteriormente en Santiago de Cuba, Villa Clara y Holguín. Los jóvenes que se incorporaron a esta modalidad de enseñanza eran desvinculados de toda actividad social, con una desorientación muy marcada. Fue una opción para enrolar a estos jóvenes en la formación del sentido de su vida y su quehacer en la sociedad.

Otros programas han sido los concernientes a la formación de maestros de primaria, secundaria básica, computación, instructores de arte, enfermeros y técnicos de la salud con los objetivos educativos de alcanzar la preparación integral de los estudiantes con sólidos conocimientos científicos y técnicos, además de la formación de valores humanos y un elevado compromiso con la comunidad en aras de un desarrollo por la equidad, justicia, solidaridad y sostenibilidad.

Como parte de esta transformación en la educación, se implementa la introducción de la dimensión ambiental en los planes de estudio de todas las especialidades.

Para nuestra Isla la Universidad Popular constituye la expresión más genuina de la extensión universitaria y está vinculada con la concepción y 
materialización del nivel superior en los lugares más apartados del país, con diferentes modalidades y planes de estudios, de acuerdo a las características de cada territorio o municipio, de sus necesidades económicas y sociales.

Surge la denominada Municipalización de la Enseñanza Superior: una modalidad de educación válida para los jóvenes egresados de los cursos de maestros y otros programas. La municipalización de la enseñanza se inició en septiembre del 2001 y consiste en la creación de Sedes Universitarias Municipales a las que acceden estos jóvenes. Sus claustros están conformados por profesionales de la comunidad que en horario nocturno, se desempeñan como profesores bajo la asesoría docente-metodológica de profesores universitarios, de reconocido prestigio y excelencia académica.

Es un reto trascendente para la universidad, pues se logra una mayor inclusión de sectores sociales con desventajas económicas y culturales. Mantiene altos índices de retención y de terminación de estudios de una población estudiantil abarcadora, con amplia participación de los sectores más humildes que no cuentan con una historia familiar de profesionales. Este reto no sólo es cuantitativo ni de representación social, sino que tiene que ver necesariamente con la excelencia académica en todo el quehacer universitario, es decir, la docencia, la investigación y la extensión.

El reto se vincula en alguna medida con las ideas que aparecen en el ensayo "La misión de la Universidad", del pensador español José Ortega y Gasset, quien fundamenta la necesidad de formar profesionales-investigadores con cultura. Sus reflexiones se dirigen a enfatizar en "para qué existe, está ahí y tiene que estar la universidad... para la enseñanza de profesiones intelectuales, la investigación científica y la preparación de futuros investigadores en la Universidad, se cultiva la ciencia misma, se investiga y se enseña a ello (...) se debe crear de nuevo en la Universidad la enseñanza de la cultura, un sistema de las ideas vivas que el tiempo posee" (3).

Consideramos que los cambios acaecidos en Cuba responden a la Declaración de Ministras y Ministros en la XVI Conferencia Iberoamericana de Educación, celebrada en Montevideo, Uruguay, del 12 al 13 de julio del 2006, donde se aboga por la articulación entre la educación superior, la investigación, el desarrollo y la innovación.

Los resultados hasta el momento son alentadores, no sólo en lo docente, sino que las sedes devienen en centros de promoción cultural, teniendo en cuenta las diferencias económicas y sociales de cada municipio, lo que significa una revitalización para la comunidad de su espacio sociocultural.

Las sedes universitarias municipales radican en las escuelas primarias y secundarias que gracias a los nuevos programas están equipadas con medios audiovisuales e informáticos, que a partir de las cinco de la tarde se transforman en la universidad de la localidad. 
Los profesores universitarios diseñaron el modelo pedagógico y organizaron la puesta en marcha de las sedes. El modelo pedagógico sustentable se concibió a partir de las posibilidades reales de nuestro sistema educativo.

Debemos apuntar cuáles son las características del modelo:

- Flexible: para que pueda adaptarse a diversas situaciones laborales, a particularidades territoriales y al ritmo individual de aprovechamiento académico del estudiante.

- Estructurado: para favorecer la organización y desarrollo del aprendizaje.

- $\quad$ Centrado en el estudiante: para que sea capaz de asumir de modo activo su propio proceso de formación y con actividades presenciales sistemáticas.

El sistema de actividades presenciales transcurre en presencia y bajo la dirección de profesores y está constituido por las tutorías individualizadas, las clases con el objetivo de brindar una información esencial sobre los contenidos a estudiar, debatir los aspectos presentados en los videos y las consultas que tienen como propósito aclarar las dudas que presenten los alumnos durante su auto preparación, que pueden ser individuales o colectivas.

La sede municipal cuenta con los servicios informáticos, bibliografía, guías de estudio, textos, videos, todos los materiales suficientes para la preparación independiente del estudiante.

\section{La dimensión ambiental en la Universalización de la Enseñanza}

1. En la actualidad, con las sucesivas catástrofes ecológicas registradas en industrias petrolíferas, químicas o nucleares, la polución en la atmósfera, lluvias ácidas, agujeros en la capa de ozono, efecto invernadero y cambios climáticos han conllevado a una toma de conciencia general de los daños que ha sufrido y sufre la naturaleza y un amplio consenso de la urgencia de conservar y proteger a la Tierra. La defensa del ambiente se ha convertido en un objetivo prioritario de todos los ciudadanos.

El surgimiento de la modernidad como oposición al dogma medieval abre posibilidades para que el hombre confirme un propósito central: alcanzar como ser racional una voluntad, un comportamiento y una actitud resolutiva que le permita obrar con un objetivo y un fin determinado. El fin y el objetivo están encaminados a obtener todo lo que sea útil, proporcione ganancias y satisfaga necesidades materiales y espirituales. La modernidad posibilita identificar poder y saber.

El sistema capitalista, a partir de la consolidación de un sistema de conocimientos, afianzó una estructura económica diferente en beneficio de empresas práctico-productivas que satisficieran demandas no resueltas y nuevas. Además, permitió el rompimiento de lazos entre la comunidad tradicional y "el yo", que se visualizó como ente separado del mundo, frente a él y con la capacidad para 
actuar sobre éste, considerándose señor de la naturaleza. La relación hombrenaturaleza estuvo sustentada en la razón como instrumento del conocimiento y al servicio de la acción práctica para resolver fines.

Pero, ¿cuál razón?, ¿la razón instrumental que indica cómo son "las cosas" para manejarlas?, o ¿la razón crítica que indica el conocimiento de "las cosas" para transformarlas, para valorarlas?

La época social nacida con el devenir del capitalismo, persigue un proceso de desarrollo industrial y científico sin precedentes y coadyuva a dar soluciones verdaderas a hechos, que en momentos anteriores del avance humano se respondían mediante la teología y la mistificación exagerada de los fenómenos que ocurrían alrededor del hombre. El mundo actual se valora de modo diferente, y con una mentalidad nueva.

La creencia de que la razón y la verdad resolverían los problemas centrales del hombre no se cumple. Realmente este ideal fue traicionado por el paradigma del capital. Todo el proceso civilizatorio estuvo y ha estado funcionando a través de un crecimiento económico y un progreso científico-tecnológico que ha permitido el sostenimiento de este sistema, con todo el saldo negativo para la humanidad.

La modernidad provocó la transformación social rápida, la potencialidad revolucionaria del desarrollo, el tránsito hacia formas económicas superiores. Pero, contradictoriamente, trajo consigo también el desencantamiento del mundo, y el dominio de una razón instrumental, cuyo centro es conquistar la naturaleza, concibiéndola un instrumento de la producción, que genera una ferocidad destructiva por parte del hombre hacia ella.

Las aseveraciones anteriores señalan la idea de que en la modernidad la relación hombre-naturaleza se torna aún más en una actitud de dominio, explotación, destrucción, degradación y manejo irracional de la naturaleza. Se concibe como mero objeto, se somete a un proceso de desustancialización y de potenciación, que la incapacita para ser -al decir de Gómez Heras- sujeto de derechos y soporte de valores (4). El hombre se distancia de la naturaleza. El objetivo es dominarla, por lo que la coloca frente a sí, la somete a un proceso destructivo, se desbastan sus recursos, a partir de una explotación, indiscriminada e irracional. Estas ideas permearon y permean la vida humana, es un sentimiento de poder, de sentirse fuerte sobre el otro. Los deseos y acciones son ingredientes esenciales en el proceso de interacción hombre-naturaleza, para un tipo de sociedad que ha traicionado la esperanza y destruido la verdad. Por supuesto, el comienzo y resultado es consecuencia del capital, que le interesa únicamente la obtención de "cosas" que devengan ganancias. Es el mito del mercado.

Será preciso retomar los planteamientos globales que vinculan estrechamente historia y naturaleza, sujeto y naturaleza. No con el fin de optar románticamente por la naturaleza, frente al sujeto o por la naturaleza frente a la 
historia. Quizás sea preciso reivindicar de nuevo una reconciliación y armonía dinámica entre el hombre, los productos de su actividad y el entorno natural. Se trataría de buscar una nueva forma de pensar con un principio básico. Tanto la realidad física-natural como la realidad valorativa-cultural no están a nuestra disposición como los productos de un supermercado. Se impulsaría un modo ambientalista de pensar que no reduzca el conjunto de la realidad natural y cultural a mero capricho de cualquier individuo, a mera arbitrariedad de quienes detenten la fuerza.

El sentido que nos ocupa es la internalización de los valores y potenciales de la naturaleza, no es ella "el otro", sino somos nosotros mismos. Al degradarla, se ha degradado al hombre mismo.

Una visión holística del mundo, es decir, la correspondencia entre las partes y el todo brindará la posibilidad de entender la articulación y la integración de la realidad plena en que vivimos y comprender desde una posición dialécticomaterialista la internalización hombre-naturaleza. Construir una nueva racionalidad desde la perspectiva ambiental, en la cual el sujeto social internalice los nuevos acontecimientos desde la interdisciplinariedad.

La racionalidad ambiental sería el resultado de un conjunto de reglas, normas, teorías, conceptos, intereses, valores, instrumentos, métodos y técnicas de producción dentro de la relación naturaleza-sociedad y está conformada por procesos sociales que traspasan las actuales estructuras de la sociedad de consumo, es decir, sustituir la actual racionalidad capitalista por una racionalidad donde se comprenda la verdadera internalización sociedad-naturaleza. Sería un concepto heurístico, dinámico y flexible para analizar y orientar las diversas cuestiones del ambiente. La racionalidad ambiental implica una crítica a la racionalidad instrumental que la civilización moderna ha impuesto $y$, por tanto, significa el desmontaje de la racionalidad económica, fundada en el mercado y el consumo, estableciendo nuevas bases culturales, naturales y de conocimiento.

El ecólogo mejicano Enrique Leff nos afirma: "La racionalidad ambiental incorpora un conjunto de valores y criterios, una estrategia conceptual que orienta la realización de los propósitos ambientales" (5).

Entonces, ¿se requiere la construcción de un nuevo paradigma moral? Sí, no es tan fácil, pero se puede y se debe. El primer paso consistiría en examinar y replantear los valores a considerar. Cambio de paradigma no significa necesariamente destrucción de los valores, sino más bien un cambio de valores:

- de una ciencia amoral a una ciencia éticamente responsable,

- de una tecnocracia dominadora del hombre a una tecnología al servicio del hombre más humano,

- de una industria de impacto medioambiental a una industria que de acuerdo con la naturaleza, fomente los auténticos intereses y necesidades del hombre, 
- de una democracia formal a una democracia viva que garantice la libertad y la justicia,

- no sólo son condenas, sino elaborar proyectos, orientaciones y alternativas que pueden favorecer la existencia humana $(\mathrm{H}$. Kung) (6).

Se trata realmente de asumir una posición de vanguardia, una posición revolucionaria que implique una clara conciencia de la situación en que vivimos y el respeto que debemos a todos. Asumir esa posición nos ayudará a entender qué debemos hacer y cómo lo debemos hacer.

Dadas las condiciones en que habitamos el Planeta, en específico, en el contexto cubano se ha ido desarrollando una serie de pasos de inestimable valor destinada a fortalecer la preparación que debemos alcanzar en este nuevo milenio en pos de la sostenibilidad, la paz, la equidad y la justicia social.

La educación en general es un proceso para toda la vida y así lo es también la educación ambiental que debe poseer un sentido crítico para la superación constante desde el punto de vista cultural de la relación humana con el ambiente, que hasta el momento es irracional.

Ahora bien, estos elementos no pueden entenderse de manera aislada, no sólo debe formar parte del sistema escolar, sino de toda la vida del ciudadano que implica internalizar el ambiente a la conciencia de cada uno.

La educación ambiental desde este punto de vista se convierte en eje central de la formación de una mentalidad que se preocupe por la satisfacción de las necesidades humanas y el vínculo esencial con la calidad de vida, pero sin afectar el bien futuro.

Significa proclamar la acción de apropiación pero en sentido educativocultural, en donde el hombre no sea un ente devorador sino un agente racional del desarrollo suyo y de los ecosistemas.

La noción de ciudadano debe ser acompañada de deberes y derechos que deben conllevar a la conciencia planetaria de protección de la naturaleza como condición de supervivencia y de calidad de vida personal. Los deberes y derechos del futuro abrigarán la idea de las nuevas reivindicaciones de la seguridad, del marco de vida, de la ampliación de los derechos de las personas; a un agua pura, a los bosques, a una atmósfera no polucionada, a un entorno natural no desfigurado, si logramos estos derechos, habremos conquistado históricamente el derecho a la calidad de vida.

La educación ambiental que se propugna desplegar debe despertar la sensibilidad, elevar el nivel de conciencia y engendrar un compromiso destinado a resolver problemas ambientales concretos; por ello es esencial la adquisición de conocimientos y la formación de actitudes que faciliten ese despertar, estimular la participación activa de los ciudadanos en la toma de decisiones para lograr la calidad de vida, generando una nueva cultura en la que se multipliquen nuevos valores compatibles con un desarrollo humano sostenible. 
En este proceso educativo es necesario lograr que los ciudadanos reflexionen sobre las complejidades del medio ambiente y adquieran conocimientos, valores, comportamientos, actitudes y conductas para actuar en la protección y conservación de éste y crear la conciencia sobre la interdependencia económica-política y ecológica del mundo contemporáneo intensificando las responsabilidades entre los países. Una educación que busque aprender y resolver problemas concretos supone, no sólo el desarrollo de conocimientos y de técnicas, sino también y ante todo prácticos.

2. De ahí que los principales problemas ambientales en Cuba que se analizan en la Estrategia Ambiental Nacional están respondiendo a lo indicado mas arriba sobre el desarrollo cultural a desplegar en los sujetos sociales.

A saber:

- degradación de los suelos,

- deterioro del saneamiento y de las condiciones ambientales,

- contaminación de agua terrestre y marina,

- deforestación,

- pérdida de diversidad ecológica.

Estos problemas detectados son estudiados y se hacen esfuerzos significativos para darle solución y manifestación de ello es el Programa Nacional de Medio Ambiente y Desarrollo que constituye las acciones que hará el país para dar solución a los problemas ambientales que por supuesto no sólo con respecto a nuestro país sino con la situación internacional existente.

Es de destacar que nuestro país, ubicado en los problemas a nivel global, desarrolla, a nivel específico, tareas importantes en cuanto a fuentes contaminantes, despliega una estrategia ambiental nacional que integre todas las necesidades de cada territorio; en la Ley 81 del año 1994 sobre el Medio Ambiente se define la Educación Ambiental como el proceso continuo y permanente, que constituye una dimensión de la educación integral de todos los ciudadanos, orientada a la adquisición de conocimientos, desarrollo de hábitos, habilidades, capacidades, actitudes y en la formación de valores morales, o sea acentuar en la armonización de las relaciones entre los seres humanos y de ellos con el resto de la sociedad y la naturaleza, para propiciar la orientación de los procesos económicos, sociales y culturales hacia el desarrollo sostenible. La definición recoge los aspectos centrales que deben lograrse en la Educación Ambiental considerando a esta como un elemento esencial para la educación integral en pos de la sostenibilidad.

Los artículos comprendidos del 46 al 56 son referidos a la Educación Ambiental, destacándose la necesidad imperiosa de la concientización a través del conocimiento de toda la población, encaminada al vínculo armónico de estos con su entorno. 
Los problemas ambientales no son producto de la fatalidad. Sus causas se encuentran más en las decisiones irracionales que se toman que en las condiciones naturales. Necesitamos un llamado a todos los hombres y en especial a los futuros profesionales.

Por ello, los estudiantes en sentido general y en particular los universitarios deben ser conscientes de que las condiciones actuales del medio ambiente son resultado de condicionantes sociales, políticas y económicas, y no de condiciones físicas. Realmente, la humanidad está llamada a revisar los criterios sobre los que basa sus comportamientos y decisiones.

El objetivo de la Educación Ambiental es transmitir un sistema de valores que se adapte mejor a la lucha por la supervivencia de la humanidad y a una mejor gestión de los recursos, incluyéndose la gestión de estos recursos a largo plazo.

No obstante, debemos subrayar que algunos valores pueden revestir una importancia particular en la Educación Ambiental y que no puede olvidarse su dimensión concreta en la educación cívica, a saber:

1. la tolerancia que debe ejercerse en el marco de los debates, discusiones sobre toma de decisiones, permitir la comprensión de las distintas posiciones,

2. la solidaridad entre personas, habitantes del mismo planeta y

3. la responsabilidad que significa ser consciente, reflexionar, implicarse y actuar ante los cruciales problemas que vivimos.

Para el logro de estos aspectos se requiere de la integración dialéctica educación ambiental-ética ambiental, que coadyuvarán a la formación de una conciencia ambiental.

El desarrollo cultural de las naciones se lacera sino aprendemos a proteger y conservar el medio ambiente y este fin sólo se logrará si hacemos que todos los seres humanos conozcan, aprehendan y tomen conciencia de su papel como parte integrante del medio ambiente, partiendo del principio del respeto hacia la cultura y la vida.

En la Conferencia Regional sobre Política y Estrategias para la Educación Superior en América Latina y el Caribe, el Académico Axel Didriksson proclamó que una de las tendencias principales de la Educación Superior para el siglo XXI es la formación de profesionales con una cultura y una conciencia ambiental. Además en el Informe de Jacques Delors, reconocido pedagogo, "Formar los protagonistas del futuro" coincide en que una cultura y conciencia ambiental para la Educación Superior resultan determinantes en el logro de una cultura de paz, solidaridad y sustentabilidad.

En estos momentos se clama por la Década de la Educación para el Desarrollo Sostenible, del 2005 al 2014, teniendo como elementos trascendente la educación solidaria, desarrolladora de una cultura plural y físicamente sostenible. Sosteniendo muy claramente la idea de lograr un proyecto plural, 
democrático y solidario, es decir cambiar el modelo de vida existente, que bajo una posición antropocentrista ha situado al hombre como centro y eje de todo lo existente, olvidando que vivimos bajo una emergencia planetaria y es necesario una interdependencia entre todos los países que pueda cambiar el status vigente.

Educar para el cambio implica reflexionar sobre el hombre mismo y lo que le circunda, sus conocimientos y acciones estarán encaminadas a la formación de valores hacia la naturaleza. Un aprendizaje diario, es un reto, puesto que es la educación para una vida mejor, justa y comprometida. Sólo es posible el cambio si formamos en los ciudadanos, nuevos principios acorde a una relación verdaderamente racional entre el hombre y la naturaleza.

Para dar respuesta a este desafío nuestra universidad debe brindar una educación que prepare a ese joven universitario a enfrentarse al mundo en que vive y en el que vivirán sus hijos, por tanto tiene que ser creativo, crítico y constante en su saber, es necesario crear conciencia de su actuación, convencer del sentido de conservar, proteger y utilizar los recursos racionalmente, en el sentido sostenible, que no sólo debe ser a estudiantes si no también a los propios profesores.

Hay que ser crítico y darnos cuenta del impacto que causamos, para ello los especialistas son los encargados del consenso que hay que lograr creando una conciencia crítica del papel que el hombre juega y de la afectación que causa y cómo esa transformación debe estar encausada en un sentido racional social ambiental, no podemos ser contemplativos ante el problema, debemos capacitarnos para capacitar al resto en pos de la sustentabilidad.

¿Podemos edificar un mundo sustentable, equitativo y apto para vivir?

El profesor alemán Hans-Peter Dürr nos habla de la sustentabilidad en el sentido siguiente:

1. Sustentabilidad ecológica: relación con una adecuada moderación de la intromisión humana en el medio ambiente y una apropiada incorporación de las actitudes del hombre en el finito ecosistema, para que no se exceda la capacidad de carga de la Tierra y no disminuya la vitalidad, productividad y flexibilidad de la biosfera en la cual se basa también la productividad.

2. Sustentabilidad social: para mantener a la humanidad como una especie sobre el planeta, garantizada por una distribución justa de los recursos de la Tierra y los bienes y servicios producidos por el hombre entre los países y sus pueblos, y una participación equitativa y activa de todas las personas en la organización de la sociedad en que viven.

3. Sustentabilidad individual del hombre: para apoyar plenamente lo que según nuestras aspiraciones es humano en él, proporcionada por una suficiente base económica y condiciones apropiadas a favor de una vida de autodeterminación suficiente, digna, significativa y feliz para todos (7). 
En este mismo sentido, Enrique Leff analiza cómo el futuro debe ser sustentable, supone la apertura a otro tipo de racionalidad, es decir, no a la económica e instrumental existente orientada a la gestión de servicio ambiental, sino construir una racionalidad ambiental fundada en el sentido de humanización de la naturaleza y naturalización del hombre como señaló Carlos Marx en el siglo XIX.

El discurso de la sustentabilidad -continúa argumentando Leff- propugna el crecimiento sostenido, condición para la supervivencia del género humano, en busca de un esfuerzo compartido por todas las naciones del orbe sin una justificación rigurosa sobre la capacidad del sistema económico para internalizar las condiciones ecológicas y sociales de este proceso, o sea equidad, justicia y democracia. La sustentabilidad ecológica es condición de la sostenibilidad del proceso económico y por lo tanto hay que reconciliar a los contrarios dialécticos: medio ambiente y desarrollo económico a través de un proceso sostenible de equilibrio ecológico e igualdad social es decir lograr una productividad ecotecnológica sostenible mediante una cultura autóctona, que tenga en cuenta una ética ambiental responsable, una democracia participativa y la productividad de la naturaleza sobre la base de una racionalidad productiva nueva (8).

Una ética ambiental responsable tiene como objetivo tratar de garantizar que el futuro sea promisorio para que las futuras generaciones puedan alcanzar el éxito en su supervivencia.

Efectivamente, estamos de acuerdo con Jorge Riechmann en su libro "Un mundo vulnerable. Ensayos sobre ética, ecología y tecnociencia" cuando nos apunta que: "Hemos de aprender a hacer más con menos; y sobre todo desengancharnos de la adicción al "siempre más" y aprender a decir "es suficiente"” (9). Por supuesto, implica respetar los límites de los ecosistemas, por lo que los sistemas socio-económicos han de ser sustentables sin deterioro de ellos, sobre los que nos apoyamos, es decir que los intereses de todo tipo y en particular los morales "valen" de igual manera los del presente que los del futuro.

Realmente, la mayor responsabilidad la tienen los países del Norte, por tanto es imprescindible una reducción sistemática del impacto ambiental de las acciones humanas. Esto debe lograrse mejorando la eficiencia ambiental de las economías, es decir, como nos señala Riechmann "producir de forma ecológicamente eficiente quiere decir minimizar el flujo de energía y materiales que recorren nuestros sistemas productivos, maximizando el bienestar que obtenemos de él" (10).

La ética del siglo XXI con relación al medio ambiente debe continuar trabajando y extendiéndose a todos los niveles de la sociedad. Se trata de una ética del género humano, en el sentido como Edgar Morin lo ha señalado recientemente, aquella que reconoce las tareas del milenio:

- trabajar para la humanización del planeta,

- lograr la unidad planetaria en la diversidad, 
- desarrollar la ética de la solidaridad, la comprensión y la responsabilidad (11).

Para entender el proceso de autovaloración que cada individuo debe hacer de sus actos y cumplir con sus deberes y responsabilidad, debe conocer el mundo en que vive, interpretarlo y transformarlo.

Una de las formas para salir de la crisis actual es enarbolar las banderas de la ética, que posibilite llevar a cabo un proceso de concientización en toda la humanidad. Recabamos de una ética inteligente, prudente, orientada en justa medida con relación a las circunstancias históricas, políticas, económicas, técnicas-científicas y sociales: la ética para la sustentabilidad.

Lograr el desarrollo de un espíritu de responsabilidad y solidaridad a partir de un enfoque holístico. Por supuesto, no se tendrán las soluciones sino existe un compromiso por parte de ciudadanos y grupos sociales, para asumir una política y un estilo de vida positivo respecto al medio ambiente, en el sentido de conservación y preservación del entorno, y una voluntad política de los estados y gobernantes que coadyuven a avalar este compromiso y actitud.

Sin dudas, la Educación Superior juega un papel importante en esa formación. Al decir de Federico Mayor "es la conciencia crítica de la sociedad" y para poder serlo tiene que formar profesionales capaces de enfrentar esa tarea.

Carlos Tünnermann afirma que "nuestras más altas casas de estudio pueden influir sobre los cambios que requieren nuestras sociedades, contribuir a avizorar los diferentes escenarios futuros y diseñar alternativas de desarrollo humano sostenible, inspiradas en los principios de equidad, democracia, justicia y libertad, fundamento insustituible de una auténtica cultura de paz". De estas palabras comprendemos el papel de las universidades y por ello el interés de que en esa formación universitaria este presente el aspecto ambiental, como problema crucial en la actualidad, que nos sitúa un desafío medular: formar ciudadanos capaces de construir una sociedad más justa y abierta (Informe del Director del CRESALC, Caracas, Venezuela, 1996) (12).

Para dar respuesta a este desafío nuestra universidad debe brindar una educación que prepare a ese joven universitario a enfrentarse al mundo en que vive y en el que vivirán sus hijos, por tanto tiene que ser creativo, crítico y constante en su saber.

Nuestro país, que no está exento de errores en su lucha por la construcción del socialismo, ha desplegado una intensa batalla por desarrollar la educación a todo el pueblo.

La educación es y seguirá siendo una inversión para el desarrollo de cualquier nación. En el mundo siguen existiendo millones de analfabetos y no podemos olvidar como hecho diferenciador que el "capital humano" es en estos momentos un factor esencial y una prioridad de primer orden para todos. La educación debe contribuir a la convivencia entre toda la humanidad y el planeta, 
los seres humanos somos responsables de la garantía de la existencia de la Tierra, tarea cardinal para todos.

La educación alcanza un papel cada vez mayor en la formación integral de los ciudadanos, sedimenta la cultura y coadyuva también a la formación de la vida, en un proceso perenne de actualización, y junto a ella, la ciencia y la tecnología como portavoces y ejecutores del progreso, en tanto fuerzas productivas y engrandecedoras de cultura.

De ahí que las instituciones de la educación superior estén en vías de transformaciones trascendentales en el esfuerzo por enfrentar los fenómenos nuevos.

Ahora bien, las transformaciones económicas, políticas, sociales, tecnocientíficas, ambientales, educacionales y culturales que se operan en el mundo tienen un carácter desigual y heterogéneo, pues el beneficio que ellas aportan es subsumido por el fenómeno de la globalización. Compréndase como la actual etapa de la economía mundial, caracterizada por las estrechas interrelaciones entre los países y que tiene su base en el desarrollo del transporte, las comunicaciones y el proceso y transmisión automatizados de información, genera además, un movimiento de creciente interdependencia entre las naciones y entre los fenómenos y procesos en los más diversos campos del actuar humano, y en particular para las naciones del Tercer Mundo suscita incertidumbre y riesgos en su futuro crecimiento, pues no cuentan con los suficientes recursos financieros para enfrentar los cambios que demanda este fenómeno.

En este contexto, la reflexión latinoamericana se vincula con el aspecto del desarrollo y del conocimiento como una urgente necesidad de nuestros países dado los cambios y las asimetrías en que los distintos grupos humanos lo aprovechan y lo sufren y que condicionan las perspectivas de avance en la economía globalizada, e inducen a procesos de transformación de las instituciones de la educación superior.

Los argumentos expuestos tienen el objetivo de mostrar el por qué en la educación cubana juega un papel central la educación ambiental.

3. La Universalización de la Enseñanza ha posibilitado una reanimación importante no sólo de la comunidad sino de la dimensión ambiental.

Queremos señalar que en el plan de estudios de la carrera Estudios SocioCulturales, una de las asociadas a las sedes municipales, se imparte la asignatura de Ecología y Sociedad, donde se tributa directamente a la formación de valores ambientalistas. En el resto de las carreras universitarias con el tipo de enseñanza presencial, se introduce la dimensión ambiental a partir de la asignatura Filosofía, Problemas Sociales de la Ciencia y la Tecnología y Ética.

El programa está concebido para que los alumnos aprendan y además tomen iniciativas propias, partiendo de cuatro principios esenciales de la Ética Ambiental que propusimos, a saber: justicia, prudencia, sensibilidad y solidaridad. Como afirmó el pedagogo Paulo Freire, el proceso de educación 
debe transcurrir en una atmósfera de diálogo entre el profesor y el alumno que favorezca el amor, la esperanza y el sentido crítico.

Los profesores deben estar conscientes de que no es una imposición sino un hecho cierto la situación ambiental de hoy. Debemos poner coto. Los especialistas somos, dentro de todos los ciudadanos, una parte substancial para poder desarrollar la conciencia ambientalista que se requiere. Por eso, con esta propuesta estamos tratando de que los estudiantes se acerquen e interioricen el problema para que puedan posteriormente actuar como actores sociales en la transmisión de la responsabilidad que tenemos todos hoy, reflexionando sobre su propia conducta moral y observar cómo puede afectar a la Tierra y a otros ciudadanos.

Federico Mayor aseguró que el "enfoque ético del futuro se alimenta de la convicción de que la solidaridad hacia las generaciones actuales y la que debe ligarnos a las generaciones futuras no se contraponen... de lo que se trata es de actuar... prever es la condición de una práctica eficaz" (13).

En la propuesta queremos lograr el desarrollo de un espíritu de responsabilidad y solidaridad a partir de un enfoque holístico. Por supuesto no se tendrán las soluciones si no existe un compromiso, por parte de ciudadanos y grupos sociales para asumir una política y un estilo de vida positivo respecto al medio ambiente, en el sentido de conservación y preservación del entorno, y una voluntad política de los estados y gobernantes que coadyuven a avalar este compromiso y actitud.

El autor C. Knapp, de la Northern Illinois University, propone algunos elementos que pueden ser válidos en el proceso enseñanza-aprendizaje, en tanto buscamos solidaridad, prudencia, sensibilidad y justicia:

- confianza y amabilidad,

- respeto a uno mismo y a los demás,

- cooperación y cohesión,

- oportunidad de participar,

- $\quad$ experiencia en la resolución de problemas y conflictos (14).

Lo que hace posible, en la forma de enseñanza como el seminario que se propone de manera conjunta profesor-estudiante, realizar un proceso activo, partiendo del respeto a los diversos criterios, como elemento clave para el desarrollo del proceso de concientización de los problemas ambientales que vivimos, en tanto el objetivo que perseguimos es el desarrollo de la actividad lectiva como un diálogo abierto y franco, y avala la idea de que en el proceso de Educación Ambiental son necesarias una serie de características que coadyuven al despliegue de una Ética Ambiental Humana.

Las transformaciones llevadas a efecto en los últimos años por la Revolución Cubana en el Sistema Nacional de Educación y en particular en la Educación Superior responden a condiciones históricas concretas de Cuba, a las exigencias del despliegue tecnocientífico, al surgimiento de las nuevas 
tecnologías de la información, las comunicaciones y las reformas educativas del mundo actual. Nuestro Sistema Nacional de Educación se encamina a la preparación integral de los estudiantes, combinando sólidos conocimientos científico-técnicos, con la formación de valores humanos que les permitan un devenir creador y multilateral de su subjetividad y de su actuar responsable como futuro profesional de la ciencia y la tecnología.

\section{Notas Bibliográficas}

(1) Martí, J. (1965) Apuntes de Martí para un discurso en Inglés. Apéndice. № 4 , Obras Completas. Tomo 23, Editorial Nacional de Cuba, p. 328.

(2) López, N. y Valdés, M. (2005) "La revolución educacional en Cuba. Nuevas prácticas educativas", en Valdés, C. y Sánchez, R. (Coord.) Ética, política y cultura desde Cuba. México, Universidad de Michoacán, p. 213.

(3) Ortega y Gasset, J. (1947) Misión de la Universidad. Tomo IV, Universidad de Occidente, Madrid, p. 177.

(4) Gómez Heras, J. (Coord.) (1997) "El problema de una ética del medio ambiente", en Ética del medio ambiente. Problema, perspectivas e historia. Madrid, Tecnos, p.31.

(5) Leff, E. (1998) "Saber ambiental". México, Siglo XXI, p.117.

(6) Valdés, C. (Coord.) (2005) "La ética ambiental y nosotros", en Selección de Lecturas Ecología y Sociedad. La Habana, Félix Varela, p. 77.

(7) Dürr, H. (1999) "¿Podemos edificar un mundo sustentable, equitativo y apto para vivir?", en Delgado C. Cuba Verde. En busca de un modelo para la sustentabilidad en el siglo XXI. La Habana, José Martí, p. 30.

(8) Leff, E. (1998) "Saber ambiental". México, Siglo XXI, p.114.

(9) Riechmann, J. (2000) "Un mundo vulnerable. Ensayos sobre ecología, ética y tecnociencia". Madrid, Los libros de la Catarata, p. 32.

(10) Riechmann, J. (2000) "Un mundo vulnerable. Ensayos sobre ecología, ética y tecnociencia". Madrid, Los libros de la Catarata, p. 40.

(11) Morín, E. (1999) "Los 7 saberes necesarios para la educación científica del futuro". Francia, UNESCO, p. 70.

(12) Tünermann, C. (1996) "La Educación Superior en el umbral del siglo XXI". Caracas, CRESALC/UNESCO, p. 2.

(13) Mayor, F. (2005) "La responsabilidad del profesional científico-técnico", en Valdés, C. Selección de Lecturas Ecología y Sociedad. La Habana, Félix Varela, p. 141.

(14) Knapp C. y Godman J.H. (1993), en Caduto, M. Guía para la enseñanza de los valores ambientales. España, UNESCO, p. 12. 


\section{Referencias Bibliográficas}

- Castro, F. (1992) "Mensaje a la Conferencia de las Naciones Unidas sobre Medio Ambiente y Desarrollo", en Suplemento del periódico Granma.

- Dürr, H. (1999) "¿Podemos edificar un mundo sustentable, equitativo y apto para vivir?", en Delgado, C. Cuba Verde. La Habana, José Martí.

- Ferry, L. (1994a) El nuevo orden ecológico. El árbol, el animal y el hombre. Madrid, Tusquets.

- $\quad$ Folch, R. (1990b) ¿Qué lo hermoso sea poderoso? Barcelona, Alfa Fulla.

- Folch, R. (1998c) Ambiente, emoción y ética. Actitudes ante la cultura de la sostenibilidad. Barcelona, Ariel.

- Jonas, H. (1995) El principio de responsabilidad. Ensayo de una ética para la civilización tecnológica. Barcelona, Herder.

- Leff, E. (1994a) Ecología y Capital. México, Siglo XXI.

- Leff, E. (1995b) “¿De quién es la naturaleza?”, en Gaceta Ecológica, N³7, Diciembre, México.

- $\quad$ Leff, E. (2001c) Epistemología Ambiental. Brasil, Cortez.

- Manifiesto por la vida. Por una ética para la sustentabilidad. Programa de las Naciones Unidas para el Medio Ambiente. (2003). México, Red de Formación Ambiental para América Latina y el Caribe.

- Morín, E. (1999) Los 7 saberes necesarios para la educación científica del futuro. Francia, UNESCO.

- Ortega y Gasset, J. (1947) “Misión de la Universidad”, en Revista de Occidente, Tomo IV, Madrid.

- Riechmann, J. (2000) Un mundo vulnerable. Ensayos sobre ecología, ética y tecnociencia. Madrid, Los Libros de la Catarata.

- Valdés, C. y otros (2004a) Selección de Lecturas Problemas Sociales de la Ciencia y la Tecnología. La Habana, Félix Varela.

- Valdés Menocal, C. (2004b) "El saber ambiental", en López Bombino, L. El saber ético de ayer a hoy. Tomo I. La Habana, Félix Varela.

- Valdés, C. y Sánchez, R. (2005c) Ética, política y cultura desde Cuba. Morelia, Universidad de Michoacán.

- Valdés Menocal, C. (2005d) Selección de Lecturas Ecología y Sociedad. La Habana, Félix Varela. 